\title{
Kulturowe i duchowe dziedzictwo narodów bałkańskich w kontekście dokumentów UNESCO ze szczególnym uwzględnieniem serbskiej slavy
}

\author{
Magdalena Ickiewicz-Sawicka \\ Katedra Ekonomi i Nauk Społecznych \\ Politechnika Białostocka \\ Polska \\ madziak11@wp.pl
}

\begin{abstract}
Magdalena Ickiewicz-Sawicka, Cultural and spiritual heritage of the peoples of the Balkans in the context of UNESCO documents on the example of the Serbian Slava, Elpis, 19 2017: 113-119.

Abstract: The article titled „Cultural and spiritual heritage of the peoples of the Balkans in the context of UNESCO documents on the example of Serbia" consists of three main parts. The first one contains a description of the cultural heritage of humanity in the light of the international instruments and presents selected theoretical concepts concerning the discussed topics. The second part refers to the cultural heritage of selected Balkan nations, the next part of the Serbian Slava presented as an example of intangible heritage of humanity nations of southern Slavs. The text contains an introduction and conclusions.
\end{abstract}

\begin{abstract}
Streszczenie: Artykuł pt. składa się z trzech zasadniczych części. Pierwsza z nich zawiera opis dziedzictwa kulturowego ludzkości w świetle dokumentów międzynarodowych oraz prezentuje wybrane koncepcje teoretyczne dotyczące poruszanej w nim tematyki. Druga część odnosi się do spuścizny kulturowej wybranych narodów bałkańskich, trzecia zaś prezentuje serbską slavę jako przykład niematerialnego dziedzictwa ludzkości narodów południowych Słowian. Tekst opatrzony jest wstępem i wnioskami końcowymi.
\end{abstract}

Keywords: culture, cultural heritage, immaterial heritage of humanity, Balkan nations, Serbian slava

Slowa kluczowe: kultura, kulturowe dziedzictwo, niematerialne dziedzictwo ludzkości, narody bałkańskie, serbska slava

„Świat kultury, tzw. noosfera, jest do życia człowiekowi równie potrzebny jak biosfera"

Antoni Kępiński

\section{Wstęp}

Dziedzictwo kulturowe (cultural heritage / patrimoine culturel) $^{1}$ jest pojęciem, które obejmuje szeroki zakres znaczeniowy. Zgodnie z Aktem Konstytucyjnym UNESCO, jednym z celów Organizacji jest ochrona „spuścizny książek, dzieł sztuki, zabytków historii i nauki (...)”. Działalność UNESCO w tym zakresie przejawiała się dotychczas w różnych formach. Obecnie dziedzictwo kulturalne UNESCO umownie dzieli się na dziedzictwo materialne obejmujące zabytki nieruchome (w tym Światowe Dziedzictwo) i ruchome oraz dziedzictwo niematerialne przekazywane przede wszystkim werbalnie i w formie tradycji. Zabytki piśmiennictwa są natomiast przedmiotem programu „Pamięć Świata” ${ }^{2}$.

K. Zeidler, Prawo ochrony dziedzictwa kultury, Warszawa 2007.

2 Program UNESCO „Pamięć Świata” (Memory of the World) został utworzony w roku 1992. Jego celem jest podejmowanie działań służących zachowaniu, ratowaniu i udostępnianiu dziedzictwa dokumentacyjnego. Na Pierwszym Spotkaniu Międzynarodowego Komitetu Doradczego Programu, które odbyło się w Pułtusku w 1993 roku, przyjęto szeroką definic-
W ciągu dziesięcioleci powstało wiele aktów normatywnych, konwencji i zaleceń, mających na celu wzmocnienie ochrony dziedzictwa kulturalnego zarówno na szczeblu krajowym, jak i międzynarodowym. Oto katalog niniejszych aktów prawnych: Akt Konstytucyjny, Konwencja o ochronie dóbr kultury w razie konfliktu zbrojnego (1954) i II Protokół z marca 1999, Konwencja dotycząca środków zmierzających do zakazu i zapobiegania nielegalnemu przywozowi, wywozowi i przenoszeniu własności dóbr kultury (1970), Konwencja w sprawie ochrony światowego dziedzictwa kulturalnego i naturalnego (1972), Konwencja dotycząca podwodnego dziedzictwa kulturalnego, Konwencja w sprawie ochrony niematerialnego dziedzictwa kulturowego (2003), Konwencja w sprawie ochrony i promowania różnorodności form wyrazu kulturowego (2005), Powszechna Deklaracja o Różnorodności Kulturowej³

Ponadto ONZ ma w swoim dorobku wiele działań, których celem jest ratowania zabytków. Dziedzictwo kul-

ję dziedzictwa dokumetacyjnego. Obejmuje ono różne typy dokumentów stanowiących przedmiot zainteresowania Programu: dokumenty i zespoły archiwalne, rękopisy przechowywane w bibliotekach i muzeach, druki o szczególnej wartości dokumentacyjnej, inskrypcje, dokumenty audiowizualne zachowane zarówno na nośniku analogowym, jak i cyfrowym, http://www.unesco.pl/komunikacja-i-informacja/pamiec-swiata/, dostęp 1.12.2016.

3 Zob. http://www.unesco.org/culture/ich/index.php?pg=00006, dostęp 1.12.2016. 
turowe uznaje się za ważny czynnik globalnego rozwoju społeczno-gospodarczego, środek poszukiwania dróg porozumienia w regionach dotkniętych konfliktami na tle etnicznym lub religijnym oraz za wyraz różnorodności kulturowej krajów i regionów świata ${ }^{4}$.

\section{Dziedzictwo kulturowe ludzkości}

W rozumieniu Konwencji UNESCO, której tekst został przyjęty na 32 sesji Konferencji Generalnej UNESCO w październiku 2003 r., dziedzictwo niematerialne to zwyczaje, przekaz ustny, wiedza i umiejętności oraz związane z nimi przedmioty i przestrzeń kulturowa, które są uznane przez daną wspólnotę, grupę lub jednostki za część ich własnego dziedzictwa. Ten rodzaj dziedzictwa jest przekazywany z pokolenia na pokolenie i ustawicznie odtwarzany przez wspólnoty i grupy $\mathrm{w}$ relacji $\mathrm{z}$ ich otoczeniem społecznym, historią czy środowiskiem naturalnym. Dla danej społeczności dziedzictwo niematerialne jest źródłem poczucia tożsamości i ciągłości.

Dziedzictwo niematerialne w rozumieniu Konwencji UNESCO obejmuje:

- tradycje i przekazy ustne, w tym język jako nośnik niematerialnego dziedzictwa kulturowego,

- sztuki widowiskowe,

- zwyczaje, rytuały i obrzędy świąteczne,

- wiedzę i praktyki dotyczące przyrody i wszechświata,

- umiejętności związane z rzemiosłem tradycyjnym.

Do czasu przyjęcia Konwencji jedynym instrumentem normatywnym UNESCO w omawianej dziedzinie były Zalecenia dotyczące ochrony kultury tradycyjnej i ludowej z 1989 roku (Recommendation on the Safeguarding of Traditional Culture and Folklore / Recommandation sur la sauvegarde de la culture traditionnelle et populaire) $)^{5}$. Polska ratyfikowała Konwencję w 2011 roku. Jej polski tekst jest opublikowany w Dzienniku Ustaw Nr 172, poz. 1018.

\section{Pojęcie kultury i dziedzictwa kulturowego - wybrane koncepcje}

W szeroko rozumianej nauce sformułowano wiele definicji kultury. Ponadto powstało gros szkół i nurtów (np. ewolucjonizm, funkcjonalizm, strukturalizm), które zwracały uwagę na różne aspekty kultury w zależności od stawianych celów badawczych i zapatrywań naukowców na życie społeczne. Konsekwencją tej różnorodności jest faktyczna nieobecność uniwersalnej definicji kultury, pomimo podejmowanych prób jej sformułowania. Jednoznaczne określenie i zintegrowanie całości wiedzy $\mathrm{z}$ tego zakresu doprowadziało do stworzenia nowej dys-

\footnotetext{
4 Zob. http://www.unesco.pl/kultura/dziedzictwo-kulturowe/, dostęp 1.12.2016.

Zob. http://portal.unesco.org/en/ev.php-URL_ID=13141\&URL_DO= DO TOPIC\&URL SECTION=201.html, dostep 1.12.2016.
}

cypliny naukowej, zwanej kulturoznawstwem ${ }^{6}$. Mimo to jednak różnice między podejściami do zagadnienia kultury, nawet w obrębie tej osobnej dziedziny nauki, są dość znaczne ${ }^{7}$

$\mathrm{Z}$ jednego punktu widzenia dla określenia, czym jest kultura, najważniejsze wydaje się uwypuklenie tego, co nie jest „naturą" i co odróżnia społeczeności ludzkie od społeczeństw zwierzęcych (choć pojawiają się też głosy akceptujące istnienie kultury tych ostatnich). Zgodnie $\mathrm{z}$ innym stanowiskiem reprezentowanym przez badaczy kultury najważniejsze jest podkreślenie różnic dzielących społeczeństwa, z których każde wytwarza właściwe sobie wierzenia, wzory postępowania, praktyki, instytucje itd ${ }^{8}$.

Drugie podejście w definiowaniu terminu „kultura” nie ma charakteru wartościującego i wyraża się w przekonaniu, że każda trwała zbiorowość posiada swoistą kulturę, zaś zadaniem badaczy jest uchwycenie cech tej kultury. Inni naukowcy uważają zaś, że „kultura” pozostaje terminem wartościującym i odnosi się jedynie do tych jednostek i grup, które stały się „kulturalne”, tj. wzniosły się powyżej poziomu prymitywizmu, dzikości, barbarzyństwa. W związku z tym można mówić o kulturach „wyższych” i „niższych”. Należy podkreślić, iż to ostatnie stanowisko jest obecnie kwestionowane.

Kolejne podejście do badania kultury uwzględnia zjawisko globalizacji (jest to tzw. globalne pojęcie kultury), obejmujące całokształt duchowego i materialnego dorobku społeczeństwa, przekazywanych z pokolenia na pokolenie wierzeń i praktyk jego członków, przyjętych przez nich wzorów postępowania itd. Dla innych kultura jest jedynie wycinkiem owej całości, składają się na nią m.in. piśmiennictwo, teatr, muzyka). Nie należą do niej natomiast przykładowo nauka czy technika ${ }^{10}$.

Rozległość problematyki kultury, zwłaszcza rozumianej globalnie, sprawiła, iż wielokrotnie podejmowano próby jej uszczegółowienia. W tym celu wyodrębniono kilka różnych jej typów (tradycyjną, ludową, nowoczesną, masową itp.), jej różnych sfer, aspektów (np. materialną, duchową, społeczną) czy takich jej względnie odrębnych dziedzin jak kultura polityczna, ekonomiczna, prawna, literacka, artystyczna ${ }^{11}$. Wszystkie powyżej wymienione cechy kultury składają się z kolei na pojęcie dziedzictwa kulturowego danej grupy czy społeczności.

W potocznym rozumieniu kulturowego dziedzictwa grupy społecznej, np. narodu, uwzględnia się nie tylko

\footnotetext{
6 W. Burszta i W. Kuligowski, Sequel. Dalsze przygody kultury w globalnym świecie, Warszawa: Wydawnictwo Literackie Muza, 2005, s. 85.

Zob. A. Kłosowska, Socjologia kultury, Warszawa 1981, M. C. Czerwiński, Kultura i jej badanie, Wrocław 1985, J. Kmita, Kultura i poznanie, Warszawa 1985.

8 Zob. http://encyklopedia.pwn.pl/haslo/kultura;3928887.html, dostęp 1.12.2016.

9 Tamże.

10 E. Nowicka, Świat człowieka - świat kultury, Warszawa 1991, Wiedza o kulturze, t. 1-4, Warszawa 1991-1993, S. Bednarek, Pojmowanie kultury i jej historii we współczesnych syntezach dziejów kultury polskiej, Wrocław 1995

11 Zob. http://encyklopedia.pwn.pl/haslo/kultura;3928887.html, dostęp 1.12 .2016
} 
tzw. kulturę osobistą jednostek, do której sprowadzałyby się pewne wzorce zachowań, ale również, zespół wytworów kultury takich jak dzieła sztuki, dzieła naukowe, narzędzia techniki, osiedla, instytucje. Elementy tego rodzaju są przekazywane z pokolenia na pokolenie i to im właśnie w znacznej mierze kultura grupy społecznej zawdzięcza swą ciągłość. W szczególności zaś dotyczy to kultur społeczeństw o bardziej rozbudowanej strukturze. $\mathrm{Z}$ perspektywy antropologicznej więc, istnienie kultury zależy ostatecznie od świadomych i czynnych jednostek ludzkich. Fakty kulturowe są sumą kolejnych doświadczeń wielu jednostek. W związku z tym żaden wzór kulturowy nie może trwać, żadne systemy kulturowe nie mogą się utrzymywać, jeżeli nieskończona różnorodność zmiennych jednostkowych doświadczeń nie będzie bezustannie ujednolicana przy pomocy wspólnych wzorców i norm ${ }^{12}$. Tak pojmowaną integralność mogą osiągnąć jedynie same jednostki stale wspópracujące ze sobą przy tworzeniu, zachowywaniu i stosowaniu tych zasad. Taka regularna współpraca wymaga świadomej interakcji społecznej pomiędzy nimi - interakcji, która jest nie arbitralna i przypadkowa, lecz kierowana przez wspólne wzorce wzajemnego doświadczania się i rozumienia oraz przez wspólne normy postępowania ${ }^{13}$. Bez względu na to, jaki ład aksjonormatywny daje się wykryć wśród czynności niespołecznych odnoszących się do przedmiotów niebędących ludźmi, warunkiem istnienia tego ładu zawsze jest dynamiczny, nacechowany aksjologicznie społeczny porządek wzajemnego oddziaływania między jednostkami wykonującymi owe niespołeczne czynności. Niezależnie od tego, jak różnorodne bywają kulturowe wzory i systemy czynności odnoszących się do takich przedmiotów, ich ciągłe istnienie zależy od pewnych zasadniczych podobieństw ładu społecznego ${ }^{14}$.

W każdej kulturze wyróżniamy cztery kategorie elementów: materialno-techniczne, społeczne, ideologiczne i psychiczne (dotyczące uczuć i postaw). Elementy te są powiązane $\mathrm{w}$ taki sposób, że stanowią harmonijną całość swego rodzaju system, strukturę. W tym rozumieniu istotne są nie tylko same elementy, ale związki łączności i zależności między nimi. To one stanowią o odrębności kultury, która nie daje się zredukować wyłącznie do sumy elementów ${ }^{15}$.

Te same części składowe występujące w poszczególnych kulturach mogą pełnić różne funkcje, występować w rozmaitych układach i w różnorodny sposób wpływać na życie społeczne. O swoistości i odrębności kultury „nie stanowi mnogość elementów ani ich oryginalność, ale powiazania między nimi, to, co nazywamy »ladem kulturowym «"16. Jeden z najwybitniejszych badaczy zagadnień

\footnotetext{
12 L. Dyczewski, Kultura polska $w$ procesie przemian, Lublin 1995, s. 37.

13 L. Dyczewski, dz. cyt., s.37.

14 R. Linton, Kulturowe podstawy osobowości, Warszawa 1975, s. 44.

15 C. Kluckhohn, Badanie kultury, [w:] Elementy teorii socjologicznych, red. W. Derczyński, A. Jasińska-Kania, J. Szacki, Warszawa 1975, s. 35$-36$.

16 F. Znaniecki, Nauki o kulturze: narodziny i rozwój, przeł. J. Szacki, Warszawa: PWN 1971, s. 676-677.
}

kulturowych, Ralph Linton, sformułował następującą definicję kultury: „Kultura jest konfiguracja wyuczonych zachowań $i$ ich rezultatów, których elementy sktadowe sa podzielane i przekazywane przez członków danego społeczeństwa"17. Inny badacz, Clyde Kluckhohn, twierdzi natomiast, że „każda kultura jest, między innymi, zespołem zależności, zbiorem uporzadkowanych i powiazanych ze soba części. Części te nie stanowia przyczyny całości, lecz sktadaja się na całość - niekoniecznie w sensie doskonałej integracji, lecz jako dające się oddzielić jedynie na drodze abstrakcji"18.

Jak pokazują powyższe rozważania, pojęcie kultury jest wieloznaczne, wewnętrzenie zróżnicowane, podlegające ciągłej zmianie i erozji. Trafną diagnozę tego pojęcia w kontekście późnej ponowoczesności proponuje Z. Bauman twiedząc, że ,...Freud już dawno zauważył, i trzeba mu przyznać absolutną rację, że »kultura nie służy żadnemu celowi, ale żadna cywilizacja nie może się bez niej obyć«. Przed nim Kant zdefiniował nawet doświadczenie kulturalne, doświadczenie artystyczne jako akt bezinteresowności. Kultura to tylko mała część, jakiś element ludzkiej egzystencji w świecie, który stanowi też o różnicy pomiędzy światem zwierząt a światem ludzi” 19 .

Ponadto zjawisko kultury, niezależnie jak zdefiniowane, generuje swoje kolejne charakterystykii określa między innymi tzw. dziedzictwo kulturowe, które stanowi główną oś rozważań w niniejszym tekście.

\section{Dziedzictwo kulturowe narodów bałkańskich - wybrane aspekty}

Zgodnie $\mathrm{z}$ zapisem $\mathrm{w}$ dokumentach międzynarodowych w Serbii znajdują się obecnie cztery obiekty dziedzictwa kulturowego UNESCO uznane za oryginalny wkład tego narodu w światowe dziedzictwo ludzkości. Są nimi: zabytkowe miasto Stari Ras z monasterem Sopoća$\mathrm{ni}^{20}$, monastyr Studenica ${ }^{21}$, ruiny rzymskiego pałacu Gale-

\footnotetext{
S. Ossowski, Więź spoleczna i dziedzictwo krwi, Warszawa 1966, s. 64.

18 R. Benedict, Wzory kultury, Warszawa 1999, C. Jenks, Kultura, Poznań 1999

19 Zob. http://natemat.pl/76737,jak-kawa-rozpuszczalna-ma-byc-natych miast-zobacz-wyklad-zygmunta-baumana-o-kulturze, dostęp 1.12.2016. 20 Zabytkowe miasto Ras z monastyrem Sopoćany (K I, III /1979) w pobliżu dawnego miasta Ras, stolicy Serbii, imponujący zespół średniowiecznych zabytków obejmujący twierdze, kościoły i klasztory, m.in. Sopoćany, przypomina o kontaktach między cywilizacją zachodnią a światem bizantyjskim. Zob. O. Datt Upadhya, The art of Ajanta and Sopoćani: a comparative study: an enquiry in prāna aesthetics, Motilal Banarsidass Publ., 1994, s. 28.

21 Monastyr Studenica (K I, II, IV, VI /1986), ufundowany przez Stefana Nemanię, założyciela średniowiecznego państwa serbskiego wkrótce po abdykacji w końcu XII w., jest największym i najbogatszym klasztorem prawosławnym w Serbii. Jego dwa główne zabytki z białego marmuru: cerkiew Bożej Bogurodzicy i cerkiew koronacyjna (Kraljeva crkva) zawierają pełny repertuar form XIII i XIV-wiecznego malarstwa bizantyjskiego. Zob. W. Felczak, T. Wasilewski, Historia Jugosławii, Wrocław: Ossolineum, 1985, s. 108
} 
riusza $^{22}$ oraz średniowieczne zabytki Kosowa ${ }^{23}$, w ramach których uwzględnione są trzy monastery i jedna cerkiew. Dodatkowo od 2002 roku na wpisanie na tę listę czeka jeszcze 11 serbskich obiektów. Dla przykładu: obiekty związane z kulturą Vinča, najstarsza kopalnia miedzi w południowo-wschodniej Europie Rudna Glava czy Lepenski Vir. Ponadto na uwagę zasługują także Twierdza w Smederevie, Petrovaradin k. Nowego Sadu i Kalemegdan w Belgradzie $^{24}$.

Narodowy Instytut ds. Ochrony Zabytków (Republički zavod za zaštitu spomenika kulture) podaje warunki, które muszą być spełnione, by konkretny obiekt architektury bądź przyrody znalazł się na liście światowego dziedzictwa UNESCO ${ }^{25}$. Zgłaszane obiekty powinny być autentyczne i oryginalne oraz zintegrowane ze społeczeństwem lokalnym i całym narodem pod względem wskazanego dobra kulturalnego czy architektonicznego..

Serbska Komisja ds. UNESCO stwierdziła, że obecnie warunki wprowadzenia nowego obiektu na listę światowego dziedzictwa są trudniejsze do spełnienia niż 40 lat temu, tuż po podpisaniu Konwencji. Wówczas to kraje Europy Zachodniej wprowadziły do spisu niemal wszystkie obiekty, którymi dysponowały. Obecnie wykazanie autentyczności danego dobra jest znacznie bardziej skomplikowane i wymaga dużego zaangażowania. Planowane są już międzynarodowe projekty, które umożliwią poszerzenie Listy światowego dziedzictwa UNESCO o kolejne obiekty z terenu Półwyspu Bałkańskiego ${ }^{26}$.

$\mathrm{Z}$ oczywistych powodów liderem pod względem liczby obiektów znajdujących się na Liście UNESCO pozostaje Grecja - kraj ten reprezentowany jest przez 17 obiektów. Pierwsza na listę wpisana została Świątynia Apollina Epikuriosa w Bassaj (w 1986 roku). Ateński Aropol dodany został w 1987 roku, a rok później do spisu trafiły klasztory

\footnotetext{
22 Pałac Galeriusa w mieście Gamzigrad (K III, IV/2007) Zespół budowli rzymskich w mieście Gamzigrad, noszących nazwę Felix Romuliana, wzniesionych na przełomie III i IV wieku przez cesarza Galeriusa Maximianusa, na który składają się: pałac cesarski, liczne posągi oraz mauzoleum cesarza i jego matki. Zob. http://www.inthessaloniki.com/en/ rotonda, dostęp 1.12.2016.

23 Średniowieczne zabytki Kosowa (K II, III, IV / 2004) W 2006 roku wpisane na Listę Dziedzictwa Zagrożonego. Cztery budowle składające się na obiekt wpisany na Listę reprezentują wysoki poziomu bizantyjskoromańskiej kultury kościelnej, która rozwijała się na Bałkanach pomiędzy XIII a XVII wiekiem. Wyróżnia ją także odrębny styl malowideł ściennych. W kompleksie położonego na obrzeżach miasta monastyru Peć znajdują się cztery przykryte kopułami cerkwie, których ściany zdobią malowidła z XIII i XIV wieku. Szczególnie cenne są freski w kościele Świętych Apostołów pochodzące z XIII i XIV wieku freski w kościele Świętej Dziewicy będące przykładem nowej odmiany stylu renesansowego, łączącego wątki zachodnio-romańskich ze wschodnimi tradycjami prawosławno- bizantyjskimi. Zob. http://www.national-geographic.pl/ blogi/archiwum/kosowo-w-poszukiwaniu-serbskich-klejnotow-w-metochii, dostęp 1.12.2016.

24 Kosowo Serbia, rzeka Beli Drim, Zabytki z Listy Światowego Dziedzictwa Kultury UNESCO, monaster Visoki Dečani Pečka Patriaršija, monaster Gračanica Peć Dečani, meczet Sinan Paszy, cerkiew Bogorodice Ljeviške w Prizren, cerkiew św. Jerzego w Prizren, cerkiew Chrystusa Pantokratora w Viskoim Dečani, Prondzyński Zygmunt. Zob. http://www. national-geographic.pl/tags/zabytki-unesco/, dostęp 1.12.2016.

25 Zob. http://www.heritage.gov.rs/cirilica/index.php, dostęp 1.12.2016.

26 Zob. http://www.svetosavlje.org/biblioteka/Obicaji/slaveiobicaji/Lat slave46.htm, dostęp 1.12.2016.
}

na górze Athos. Najnowszą grecką pozycją na Liście UNESCO jest stare miasto w Korfu.

Bułgaria była jednym z pierwszych krajów w regionie, którego obiekty trafiły na Listę UNESCO już w roku 1979. Były to kolejno: Cerkiew Bojańska koło Sofii, Jeździec Tracki z Madary, zespół cerkwi wykutych w skale w Iwanowie i grobowiec tracki z Kazanłyku. Obecnie na na Liście znajduje się 9 obiektów i miejsc.

Jeżeli chodzi zaś o Rumunię, na Liście UNESCO znajduje się obecnie siedem obiektów i miejsc z tego kraju zarówno delta Dunaju, malowane cerkwie północnej Mołdawii, jak i stare miasto Sighisoary ${ }^{27}$.

Trzy obiekty z Listy znajdują się na terenie Słowenii Jaskinie Szkocjańskie, prehistoryczne osady na palach (są one dziedzictwem wspólnym Słowenii, Austrii, Francji, Niemiec, Szwajcarii i Włoch) oraz kopalnie rtęci (wspólne dla Słowenii i Hiszpanii). W 2012 roku na Listę dopisano jedenasty obiekt pochodzący z Turcji - stanowisko neolityczne Çatalhöyük, zaś 8 lipca 2015 roku podczas 39 sesji komitetu Światowego Dziedzictwa w Bonn certyfikat UNESCO uzyskał Efez - najprawdopodobniej najlepiej zachowane starożytne miasto regionu Morza Śródziemnego. Efez był rzymskim portem, ośrodkiem kultu boginii płodności Kybele oraz domem jednej z pierwszych wspólnot chrześcijańskich. To tutaj ostatnie lata życia spędził św. Jan Ewangelista, zaś św. Paweł mieszkał w tym mieście przez trzy lata. Na liście UNESCO znalazły się także następujące obiekty: Biblioteka Kelsosa (gr. Celsus), Świątynia Artemidy - jako jeden z siedmiu starożytnych cudów świata - Fontanna Trajana, Kościół Marii Panny, Gimnazjon i łaźnie portowe, Droga Arkadyjska, Fontanna hellenistyczna, Wielki Teatr, Brama Mazeusa i Mithrydatesa, Łaźnie Scholastyki oraz Świątynia Hadriana ${ }^{28}$.

$\mathrm{Na}$ Liście światowego dziedzictwa zostały także umieszczone Forteca Diyarbakir oraz Ogrody Hevsel położone u brzegów górnego Tygrysu w Turcji. Ufortyfikowane miasto wraz $\mathrm{z}$ okalającym je terenem było ważnym ośrodkiem począwszy od czasów hellenistycznych przez panowanie Rzymu, Sasanidów, Bizancjum, Imperium Osmańskiego do czasów współczesnych. Doceniony zespół zabytków składa się z Amida Mound, czyli zamku wewnętrznego, niemalże sześciokilometrowych murów miejskich z wieloma wieżami, bramami i przyporami, 63 inskrypcji z różnych okresów oraz Ogrodów Hevsel, które rozciągają się między miastem a rzeką Tygrys i stanowiły niegdyś o zaopatrzeniu miasta w wodę i żywność ${ }^{29}$.

W 1979 do spisu UNESCO trafiły też zabytkowe centrum chorwackiego Splitu wraz z pałacem Dioklecjana, stare miasto w Dubrowniku i Park Narodowy Jezior Plitwickich. Najnowszym, siódmym dobrem wpisanym na

\footnotetext{
27 Zob. //www.unesco.pl/no cache/kultura/dziedzictwo-kulturowe/swia towe-dziedzictwo/lista-swiatowego-dziedzictwa/europa-i-amerykapolnocna/serbia/?print=1, dostęp 1.12.2016.

28 Zob. http://turystyka.wp.pl/gid,17692123,kat,1036543,title,Noweobiekty-na-liscie-UNESCO-Europa-i-Bliski-Wschod,galeria.html, dostęp 1.12.2016.

29 Zob. http://turystyka.wp.pl/gid,17692123,kat,1036543,title,Noweobiekty-na-liscie-UNESCO-Europa-i-Bliski-Wschod,galeria.html,dostęp 1.12.2016
} 
Listę pod flagą Chorwacji, jest krajobraz kulturowy wyspy Hvar. Czarnogóra natomiast zaistniała na Liście dzięki miastu Kotor - regionowi przyrodniczemu i kulturowo-historycznemu oraz dzięki Parkowi Narodowemu Durmitor. W Macedonii zaś za dziedzictwo UNESCO uznano jedynie miasto Ochryda wraz z jeziorem Ochrydzkim. W pobliskiej Albanii z kolei zarejestrowano dwa architektoniczne obiekty: są nimi zespół archeologiczny w Butrint i historyczne centra miast Berat i Gjirokastra.

W 2005 roku Lista wzbogaciła się o pierwszy zabytek bośniacki - dzielnicę Starego Mostu w Mostarze. Dwa lata później dodano do niej również Most Mehmeda Paszy Sokolovicia w Višegradzie.

\section{Serbska Slava jako przykład niematerialnego dziedzictwa ludzkości}

Pod koniec listopada 2014 roku serbska slava (porodična slava, krsna slava), czyli święto patrona rodu, została wpisana na listę niematerialnego dziedzictwa kulturowego UNESCO. Decyzję o umieszczeniu tego narodowego zwyczaju na Liście podjął Międzyrządowy Komitet ds. Ochrony Niematerialnego Dziedzictwa Kulturowego.

W 2010 roku Serbia ratyfikowała Konwencję UNESCO w sprawie ochrony niematerialnego dziedzictwa kulturowego ludzkości. W tym samym roku rozpoczęto procedurę wprowadzania Konwencji w życie, a za jej wdrażanie odpowiedzialne jest Ministerstwo Kultury i Informacji. Do wpisania na listę UNESCO Slavę zarekomendowało Muzeum Etnograficzne w Belgradzie, wskazując na jej szczególne znaczenie dla serbskiego narodu i podkreślając że zwyczaj ten jest przede wszystkim symbolem wspólnoty. Ponadto Serbia zaproponowała także, aby na liście reprezentatywnej umieścić również kolo ${ }^{30}$ (odpowiedni wniosek został już przygotowany). W krajowym rejestrze niematerialnego dziedzictwa Serbii znajduje się obecnie 27 elementów $w^{31}$.

Slava (porodična slava, krsna slava) od wielu wieków stanowi serbski znak rozpoznawczy. Jest to uroczystość poświęcona świętemu danej rodziny, tj. jej patronowi oraz opiekunowi. „Slava” jest najpowszechniejszą, ale nie jedyną nazwą tej uroczystości. W zależności od regionu można spotkać między innymi takie określenia jak: „krsno ime”,

\footnotetext{
30 Serbski folklor podlega silnym podziałom regionalnym, każda część kraju ma swoją własna specyfikę widoczna zarówno w muzyce, jak i w tańcu. Niezmiennie jednak jego podstawą jest kolo, taniec wykonywany zbiorowo, najczęściej rytmy oparty na rytmach nieparzystych. Najbardziej popularne są vlaszko kolo, szumadijsko kolo czy też nietypowe czarnogórskie nemo (nieme) kolo, wykonywane bez akompaniamentu muzyki. Każdy region ma swoją tradycję. Poszczególne tańce, pomimo pozornego podobieństwa, potrafią się od siebie bardzo różnić. Kolo towarzyszy Serbom przy wszelkich okazjach - prawie zawsze, gdy pojawia się muzyka grana na żywo. Jest to więc tradycja będąca elementem kultury życia codziennego i, co ważne, cieszy się dużą popularnością wśród ludzi młodych http://www.muzykaduszy.pl/taniec-serbski, dostęp 1.12.2016.

31 Zob. http://balkanistyka.org/serbska-slava-na-liscie-niematerialnegodziedzictwa-kulturowego-unesco/, dostęp 1.12.2016
}

„,služba”, ,sveti”, ,,svetac”, ,,blagdan”. Najczęściej slavy przypadały na dzień św. Mikołaja (Nikoljdan - 19 grudnia, czyli św. Mikołaja z Miry). Znaczna liczba prawosławnych wiernych obchodzi ten dzień jako swoją slavę ${ }^{32}$. Św. Mikołaj uważany jest za patrona marynarzy i żeglarzy oraz wszystkich podróżujących. Na przestrzeni wieków stał się jednym z najpopularniejszych prawosławnych świętych. Na ikonach najczęściej przedstawiany jest $\mathrm{w}$ omoforionie arcybiskupa, dzierży też w ręku Ewangelię. Ponadto slavy świętuje się przy okazji innych uroczystości religijnych np .św. Michała Archanioła (Aranđelovdan - 24 listopada), św. Jerzego (Đurđevdan - 6 maja), św. Jana (Jovandan - 20 stycznia), św. Dymitra (Mitrovdan - 8 listopada), Đurđic (16 listopada) oraz św. Paraskewy (sv. Petka -27 października $)^{33}$.

Serbska rodzina była zawsze silnie związana z określonym świętym, którego uczynili swoim opiekunem. $\mathrm{Z}$ tego też powodu nigdy nie zmieniano rodowej slavy, była ona przekazywana z pokolenia na pokolenia, $\mathrm{z}$ ojca na syna. Uważano ją za symbol rodowej tożsamości. Rzadko dochodziło do zmiany patrona, chyba że dotychczasowy opiekun „opuścił” daną rodzinę np. nie uchronił przed śmiercią, chorobą czy innym nieszczęściem. Zmiana slavy następowała poprzez określony rytuał ${ }^{34}$.

Slava ma charakter zarówno religijny, jak i społeczny. $\mathrm{Z}$ czasem ten drugi aspekt zaczął dominować, niekiedy stając się jedynym. To przede wszystkim dzień, w którym dana rodzina przygotowuje odświętną ucztę dla licznych gości: krewnych, sąsiadów, przyjaciół. Wizyta zawsze musi być odwzajemniona, jeśli któraś ze stron nie wykona tego rytuału, oznacza to zerwanie dotychczasowych więzi i ograniczenie kontaktów. Slava to wyraz gościnności i otwartości, trwałej przyjaźni, która powinna być nieprzerwana i odwzajemniana ${ }^{35}$.

Według tradycji świętowanie slavy trwało trzy dni, ale w niektórych regionach kraju uroczystości mogły być przedłużane np. w Czarnogórze czy Sandżaku (serbska Raszka) świętowano trzy dni przed slava, a kończono trzy dni po święcie. Obecnie slava trwa jeden, ewentualnie dwa dni. Jej obchody rozpoczynano nabożeństwem w cerkwi, gdzie prawosławny kapłan błogosławił slavski kolač (kołacz) i koljivo (gotowaną pszenicę), polewając je winem. Następnie kroił kołacz i przekazywał wiernym.

Niemniej jednak sebska slava była przede wszystkim uroczystością rodzinną. Pierwotnie łamanie się kołaczem następowało w wigilię poprzedzającą slavę. Najczęściej kołacz łamano w dzień samej slavy, często w porze obiadu. Ceremonię odprawiali gospodarz wraz z kapłanem lub wybranym gościem zwanym kolačarem bądź dolibašom. Był to najczęściej najstarszy lub najważniejszy, szczególnie szanowany gość (pierwszy przybysz lub batlija, czyli ten, który przynosi szczęście). Inym razem kołacz łamał

\footnotetext{
32 D. Bandić, Narodno pravoslavlje, Belgrad 2010.

M. B. Petrovich, J. Halpern (1980), Serbs, [w:] S. Thernstrom, A. Orlov, O. Handlin, Harvard Encyclopedia of American Ethnic Groups, 2nd ed., Harvard University Press, p. 925.

34 D. Bandić, Narodna religija Srba u 100 pojmova, Belgrad 1991.

35 D. Bandić, dz. cyt, s. 52
} 
sam gospodarz, trzymając go nad swoją głową. Istniały także, w zależności od regionu, inne rytuały odprawiane podczas slavy. Oprócz slavy rodowej istnieje również seoska slava ${ }^{36}$, czyli slava obchodzona przez daną społeczność, ale ograniczone ramy tego opracowania nie pozwalają na głębszą analizę. Opisywane święto obchodzone jest na różnych poziomach, a jego kultywowanie trwa do dnia dzisiejszego będąc namacalnym dowodem serbskiej tożsamości i przynależności do chrześcijańskiego dziedzictwa kulturowo-religijnego ludzkości.

\section{Podsumowanie}

W podsumowaniu powyższych rozważań należy wyraźnie zaznaczyć, że niematerialne dziedzictwo ludzkości UNESCO stanowi istotny element propagowania różnorodności i bogactwa ludzkiego dorobku w dziedzinie kultury i sztuki. Podkreśla też oryginalny charakter poszczegól-

36 Zob.: http://vukajlija.com/seoska-slava/362883, dostęp 1.12.2016. nych zwyczajów, zaznaczając tym samym równoprawność kultury niematerialnej, która stanowi nieodzowny element kulturowej aktywności i różnorodności narodów czy grup etnicznych zamieszkujących ziemię. Kultura niematerialna wzmacnia siłę kultury materialnej będącej niejednokrotnie przejawem, ucielśnieniem zwyczajów np. w obiekcie sakralnym odbywają się rytuały identyfikujące daną społeczność. W związku z tym obie kultury przenikają się i uzupełniają wzajemnie, tworząc cenne dziedzictwo kulturowe ludzkości. W przypadku chrześcijańskich narodów bałkańskich jest nim serbska slava.

Znaczenie slavy oraz jej celebrowanie pozostały niezmiennie istotne dla serbskiej tradycji i kultury. Serbowie świętowali ją znajdując się pod panowaniem tureckim, w czasach licznych bałkańskich wojen oraz podczas komunistycznego reżimu J. B. Tity. Slava to serbska tożsamość, symbol narodowej jedności i tradycyjnych wartości, a także wyraz przywiązania do chrześcijańskich (prawosławnych) wartości, potwierdzających przynależność do europejskiego kręgu kulturowego.

\section{Bibliografia}

Petrovich Michael B., Joel Halpern, Serbs [w:] S. Thernstrom, A. Orlov, O. Handlin. Harvard Encyclopedia of American Ethnic Groups (2nd ed.). Harvard University Press 1980. p. 925.

Bandić D, Narodno pravoslavlje, Belgrad 2010.

Bandić D., Narodna religija Srba u 100 pojmova, Beograd Nolit. Beograd 1991.

Bednarek S.,Wiedza o kulturze, t. 1-4, Warszawa 1991-1993., Pojmowanie kultury i jej historii we wspótczesnych syntezach dziejów kultury polskiej, Wrocław 1995.

Benedict R. , Wzory kultury, Warszawa 1999,

Burszta W., Kuligowski W., Sequel. Dalsze przygody kultury w globalnym świecie, Warszawa: Wydawnictwo Literackie Muza, 2005, s. 85.

Czerwiński M., Kultura i jej badanie, Wrocław 1985.

Dyczewski L., Kultura polska w procesie przemian, Lublin 1995 , s. 37.

Felczak W., Wasilewski T., Historia Jugosławii, Wrocław: Ossolineum, 1985, s. 108.

Jenks C., Kultura, Poznań 1999.

Kmita J., Kultura i poznanie, Warszawa 1985.

Linton R., Kulturowe podstawy osobowości, Warszawa 1975, s. 44.

Nowicka E., Świat człowieka - świat kultury, Warszawa 1991.

Om Datt Upadhya, The art of Ajanta and Sopoćani: a comparative study: an enquiry in prāna aesthetics, Motilal Banarsidass Publ., 1994, s. 28.

Ossowski S., Więź społeczna i dziedzictwo krwi, Warszawa 1966, s. 64.

Zeidler K., Prawo ochrony dziedzictwa kultury, Warszawa 2007. Znaniecki F., Nauki o kulturze: narodziny i rozwój, przeł. J. Szacki, Warszawa: PWN 1971, s. 676-677.

\section{Źródła internetowe}

Dziedzictwokulturowe:http://www.unesco.pl/kultura/dziedzictwo -kulturowe/, dostęp, (1.12.2016).

http://www.national-geographic.pl/blogi/archiwum/kosowo-wposzukiwaniu-serbskich-klejnotow-w-metochii, dostęp (1.12. 2016).

http://www.national-geographic.pl/tags/zabytki-unesco/, dostęp (1.12.2016).

hasło: „kultura”, http://encyklopedia.pwn.pl/haslo/kultura;39288 87.html, dostęp, (1.12.2016).

Lista światowego dziedzictwa kulturowego UNESCO www. unesco.pl/no_cache/kultura/dziedzictwo-kulturowe/ swiatowe-dziedzictwo/lista-swiatowego-dziedzictwa/ europa-i-ameryka-polnocna/serbia/?print=1, dostęp (1.12. 2016).

Ljubomir Ranković,Verski Obćaji, http://www.svetosavlje.org/ biblioteka/Obicaji/slaveiobicaji/Lat_slave46.htm, dostęp (1.12.2016).

Nowe obiekty na liście UNESCO Europa i Bliski Wschód http://turystyka.wp.pl/gid,17692123,kat,1036543,title,Nowe-obiekty-na-liscie-UNESCO-Europa-i-Bliski-Wschod,galeria. html, dostęp (1.12.2016).

Program UNESCO „Pamięć Świata” (Memory of the World) http:// www.unesco.pl/komunikacja-i-informacja/pamiec-swiata/, dostęp (1.12.2016).

Recommendation on the Safeguarding of Traditional Culture and Folklore http://portal.unesco.org/en/ev.php-URL

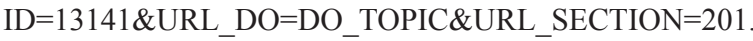
html, dostęp, (1.12.2016).

Seoska slava, http://vukajlija.com/seoska-slava/362883, dostęp (1.12.2016). 
Serbska slava na liście niematerialnego dziedzictwa kulturowegoUNESCO,http://balkanistyka.org/serbska-slava-na-liscieniematerialnego-dziedzictwa-kulturowego-unesco/, dostęp (1.12.2016).

Serbski taniec narodowy kolo, http://www.muzykaduszy.pl/taniec-serbski, dostęp (1.12.2016).

UNESCO, http://www.unesco.org/culture/ich/index.php?pg=00006, dostęp (1.12.2016). http://natemat.pl/76737,jak-kawa-rozpuszczalna-ma-byc-natychmiast-zobacz-wyklad-zygmunta-baumana-o-kulturze, dostęp (1.12.2016).

Републички завод зазаштиту споменика културе - Београд http://www.heritage.gov.rs/cirilica/index.php, dostęp (1.12. 2016).

http://www.inthessaloniki.com/en/rotonda, dostęp (1.12.2016).

Rozmiar artykułu: 0,8 arkusza wydawniczego 
ISSN 1508-7719

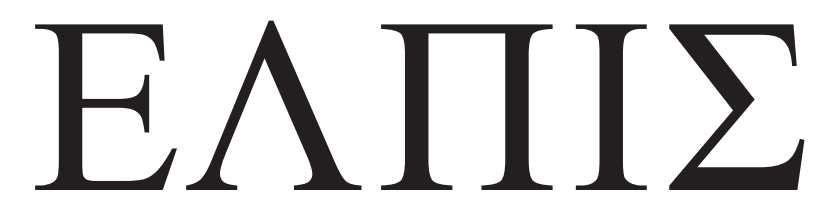

CZASOPISMO TEOLOGICZNE KATEDRY TEOLOGII PRAWOSŁAWNEJ UNIWERSYTETU W BIAŁYMSTOKU

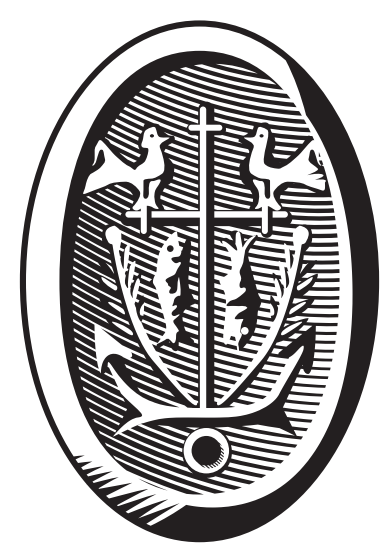

ADRES REDAKCJI

15-097 Białystok, ul. M. Skłodowskiej-Curie 14 tel. 85 745-77-80, e-mail: redakcja@elpis.edu.pl www.elpis.uwb.edu.pl 